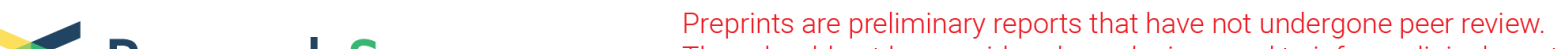 Research Square
Thr ef should not be considered conclusive, used to inform clinical practice,
on the media as validated information.
}

\section{Intubation Timing as Determinant of Outcome in Patients with Acute Respiratory Distress Syndrome by SARS-CoV-2 Infection}

\section{Magdalena Vera}

Pontificia Universidad Católica de Chile: Pontificia Universidad Catolica de Chile

\section{Eduardo Kattan}

Pontificia Universidad Católica de Chile: Pontificia Universidad Catolica de Chile

\section{Pablo Born}

Pontificia Universidad Catolica de Chile

\section{Elizabeth Rivas}

Pontificia Universidad Católica de Chile: Pontificia Universidad Catolica de Chile

\section{Macarena Amthauer}

Pontificia Universidad Católica de Chile: Pontificia Universidad Catolica de Chile

Annael Nesvadba

Pontificia Universidad Católica de Chile: Pontificia Universidad Catolica de Chile

\section{Barbara Lara}

Pontificia Universidad Católica de Chile: Pontificia Universidad Catolica de Chile

\section{Isabel Rao}

Pontificia Universidad Catolica de Chile

\section{Eduardo Espíndola}

Pontificia Universidad Catolica de Chile

\section{Luis Rojas}

Pontificia Universidad Católica de Chile: Pontificia Universidad Catolica de Chile

\section{Glenn Hernández}

Pontificia Universidad Católica de Chile: Pontificia Universidad Catolica de Chile

\section{Guillermo Bugedo}

Pontificia Universidad Católica de Chile: Pontificia Universidad Catolica de Chile

Ricardo Castro ( $\square$ rcastro@med.puc.cl)

Pontificia Universidad Catolica de Chile https://orcid.org/0000-0002-0978-9891

\section{Research}

Keywords: SARS-CoV-2, COVID-19, ARDS, Mechanical ventilation 
Posted Date: March 1st, 2021

DOl: https://doi.org/10.21203/rs.3.rs-252161/v1

License: (c) (i) This work is licensed under a Creative Commons Attribution 4.0 International License. Read Full License 


\section{Abstract}

Background: SARS-CoV-2 infection presents in many cases with pneumonia and respiratory failure. It is not clear whether the time of intubation and connection to mechanical ventilation (MV) in this condition is associated with an increase in mortality or represents the natural course of the disease.

We conducted an observational, prospective, single-center study to describe the characteristics and outcomes of acute respiratory distress syndrome (ARDS) patients with confirmed COVID-19 and treated with invasive MV to determine whether the time-to-intubation following hospital admission is associated with worse outcomes.

Methods: We prospectively included consecutive patients with SARS-CoV-2 infection and moderate to severe ARDS, admitted to an intensive care unit (ICU) and connected to MV between March 17 and July 31,2020 . We examined their general characteristics, ventilatory management, and clinical outcomes. Time of intubation was defined as the time from hospital admission to endotracheal intubation and was categorized as early ( $<72$ hours) or late ( $\geq 72$ hours). Mann-Whitney $U$, Kruskal Wallis, chi-square, and Fisher's exact, were used when appropriate. Uni and multivariate analyses between main outcome and explanatory variables were performed.

Results: A total of 183 consecutive patients were included, 28\% (51/183) were female, and their median age was 62 years [54-70]. One hundred (55\%) patients were subjected to early and 83 (45\%) to late intubation. Patients intubated after 72 hours were older and presented more comorbidities. Mortality was higher in the group of patients with late intubation ( $41 \%$ versus $21 \% ; \mathrm{p}=0.002$ ), a $\mathrm{PaO}_{2} / \mathrm{FiO}_{2}$ ratio $<100$ $\mathrm{mmHg}$ at admission $(p=0.029)$, and that were older than 60 years $(p=0.008)$.

\section{Conclusions}

In acute COVID-19 patients with moderate to severe ARDS, intubation after 72 hours following hospital admission, age $>60$ years-old and a $\mathrm{PaO}_{2} / \mathrm{FiO}_{2}$ ratio $<100$ at admission may appear to be associated with increased ICU mortality. Further studies are required to confirm our findings and establish the best timing for intubation in COVID-19 patients admitted to the ICU with respiratory failure.

\section{Background}

Pneumonia associated to SARS-CoV-2 (COVID-19) may evolve to acute respiratory distress syndrome (ARDS), which is associated with a high mortality risk (1)(2)(3)(4). Many patients are admitted with pneumonia and arterial hypoxemia without evidence of dyspnea, increased work of breathing or impending fatigue(5)(6)(7). Long-accepted clinical practice and expert consensus support prompt intubation of patients with severe hypoxemia (8)(9). However, due to the high demand for intensive care unit (ICU) beds during the pandemic (6), some authors have advocated for a conservative approach, promoting high-flow nasal cannula (HFNC) (10), or non-invasive ventilation (11) while the patient is in an awake prone position (12)(11)(10). 
Apart from the well-known risks of mechanical ventilation (MV), as infection (13) and ventilator-induced lung injury (14)(15), among others, potential shortage of ICU resources related to massive demand for MV during the pandemic has added stress and uncertainties to clinicians managing these acute patients (16). Furthermore, many of these patients exhibited a highly unstable condition, worsening after an initial improvement and eventually required intubation. It is not clear whether time-to-intubation directly associates with increased mortality in COVID-19 hypoxemic patients (17).

A recent study showed that neither time from ICU admission to intubation nor HFNC use were associated with increased mortality (18) in a time frame of 8 hours. However, different criteria may influence the moment of admission to the ICU, ranging from the initial clinical impression despite poor oxygenation, to bed-availability. Unlike ICU admission, hospital admission is objectively based on hypoxemia with diverse manifestations of dyspnea or increased work of breathing (WOB) in COVID-19 patients.

Our main objective was to determine whether the time-to-intubation in COVID-19 patients following hospital admission is associated with outcomes. To address this issue, we analyzed a prospectively collected database of mechanically ventilated COVID-19 patients treated in our ICU during the peak months of the pandemic.

\section{Materials And Methods}

This prospective observational study was carried out at the Clinical Hospital of the UC-CHRISTUS Health Network, in Santiago, Chile. Patients with laboratory confirmed SARS-CoV-2 infection and moderate to severe ARDS (19), were consecutively included between March 17 and July 31, 2020. Admission pathways comprised the emergency department, and basic ward.

The Institutional Ethics Committee approved this project (Research Ethics Committee № 200504004, Faculty of Medicine, Pontificia Universidad Católica de Chile), and waived the need for informed consent.

Laboratory confirmation of SARS-CoV-2 was defined as a positive real-time reverse transcriptase polymerase chain reaction (RT-PCR) result of nasal and pharyngeal swabs.

Our university hospital has a 32-bed both medical-and-surgical ICU with extracorporeal membrane oxygenation (ECMO) capability. Due to the COVID-19 pandemic, the hospital ICU capacity was surged incorporating up to 56 beds from other reconverted units, as needed.

Intensivists and ICU-trained nurses were deployed to these expanded ICUs to ensure a similar standard of care.

All patients undergo an initial respiratory failure management protocol that includes HFNC and the awake prone positioning if tolerated. Orotracheal intubation and connection to MV was performed if the patient had an increased WOB (tachypnea $>30$ / min and the use of accessory muscles, paradoxical breathing, altered consciousness, or an hyperadrenergic state), refractory hypoxemia (02 saturation $<90 \%$ despite prone position and HFNC at maximum fraction of inspired oxygen (FiO2) or the presence of concomitant 
shock (Additional file 1). The decision to intubate was by attending physicians, and MV started in the volume-control ventilation mode according to local management protocol (Additional file 1).

Data Collection

Data were recorded prospectively by the research team in an electronic worksheet. The study data were recorded prospectively by the research team during the patient's stay in the ICU and collected and managed using the REDCap electronic data capture tools hosted at Pontificia Universidad Católica de Chile.

Clinical data included sex, age, weight, height, medical comorbidities, days since the start of symptoms, laboratory parameters, and $\mathrm{PaO}_{2} / \mathrm{FiO}_{2}$ ratio by the time of hospital admission. The Acute Physiology and Chronic Health Evaluation (APACHE) (20) and Sequential Organ Failure Assessment (SOFA) scores(21) were calculated within 24 hours of ICU admission. Subsequently, clinical, laboratory and ventilatory parameters were recorded both on day 1 from the start of invasive MV and included: respiratory support mode, positive end-expiratory pressure (PEEP) level, arterial blood gases and $\mathrm{F}_{1} \mathrm{O}_{2}$, and respiratory system compliance (Crs).

\section{Outcomes}

Time of intubation was defined as the time from hospital admission to endotracheal intubation, and classified as lower than 72 hours (early) and equal or higher than 72 hours (late), according to published data (17) and authors consensus. The primary outcome was in-hospital death after receiving MV. Secondary outcomes included duration of MV, ICU and hospital length of stay, and mortality on day 28 and on discharge from the ICU.

\section{Statistical Analysis}

For variables with non-normal distribution, non-parametric tests were used. Accordingly, descriptive statistics are shown as medians [interquartile range 25-75] or percentages (\%). Mann-Whitney U, Kruskal Wallis, chi-square, and Fisher's exact, were used when appropriate. We performed univariate analyses between main outcome and clinical and laboratory variables. Those with a univariate $p$-value of 0.1 were included in the multivariate analysis plus other clinically relevant ones. Logistic models were fitted testing individual and interaction variables. Multivariable fractional polynomial methods were also used in order to preserve the continuous nature of important covariates as $\mathrm{PaO}_{2} / \mathrm{FiO}_{2}$ ratio, time to intubation and age, since we did suspect that their relationships with other variables were non-linear.

As mentioned, for hypoxemia and intubation times we used published cutoffs (17).

We did not use APACHE II for fitting multivariate models to avoid overadjustment, since age was incorporated as an individual variable or in the CALL score, $\mathrm{PaO}_{2} / \mathrm{FiO}_{2}$ ratio was a relevant individual variation, and comorbidities were represented in the regression models, as well. 
Data was analyzed using Graphpad Prism 7 (Graphpad Softwares, La Joya, CA), and Stata 16 (StataCorp, College Station, TX. USA) statistical packages. Two-tailed $p$ value of $<0.05$ was considered as statistically significant.

\section{Results}

During the study period, 1233 patients with confirmed COVID-19 were admitted, of which 350 evolved with $\mathrm{PaO}_{2} / \mathrm{FiO}_{2}$ ratio $<200 \mathrm{mmHg}$. Of these, $25(7.1 \%)$ patients, underwent a limitation on life-support techniques. Fifty-nine (16.9\%) patients were intubated upon admission to the ICU, while 266 (76\%) underwent a HFNC and/or prone trial, of which 142 (53.4\%) patients did not require MV during hospitalization. Thus, 183 patients with confirmed COVID-19 required invasive ventilatory support and were included in the study (Fig. 1)

Demographic and clinical characteristics of patients are shown in Table 1. Overall, 132 patients $(78 \%)$ were men, their median age was 62 years (54-70), and 138 patients (75\%) had one or more comorbidities being hypertension (48\%), diabetes (33\%) and other cardiovascular diseases (8.2\%) the most common. 
Table 1

Clinical characteristics, severity scoring and relevant outcomes of patients with severe COVID-19 respiratory failure according to timing from admission to orotracheal intubation.

\begin{tabular}{|c|c|c|c|c|}
\hline & All & $<72$ hours to 01 & $>72$ hours to 01 & $\begin{array}{l}\text { P- } \\
\text { value }\end{array}$ \\
\hline Number & 183 & 100 & 83 & \\
\hline Age (years) & $62[54-70]$ & $60[52-68]$ & $64[55-71]$ & 0.04 \\
\hline Female (\%) & $51 / 183(28 \%)$ & $29 / 100$ (29\%) & $21 / 83(25 \%)$ & 0.6 \\
\hline \multicolumn{5}{|l|}{ Comorbidities } \\
\hline Diabetes Mellitus (\%) & 61/183 (33\%) & $29 \%(29 / 100)$ & $47 \%(32 / 83)$ & 0.01 \\
\hline Hypertension (\%) & $87 / 183(48 \%)$ & $48 / 100(48 \%)$ & $39 / 83(47 \%)$ & 0.9 \\
\hline BMI (kg/m2) & 29 [27-32] & 30 [28-33] & $28[26-31]$ & 0.007 \\
\hline APACHE score & $12[8-17](139)$ & $12[8-16]$ & $13[8-20]$ & 0.5 \\
\hline SOFA score & $5[3-8](139)$ & $5[3-8]$ & $5[2-8]$ & 0.4 \\
\hline CALL Score & $11[9-12]$ & $10[8-12]$ & $11[10-12]$ & 0.02 \\
\hline \multicolumn{5}{|l|}{ Laboratory values } \\
\hline Ferritin (ng/mL) & 1449 [809-2168] & 1449 [809-2168] & $\begin{array}{l}1450[1002- \\
2359]\end{array}$ & 0.8 \\
\hline D-Dimer (ng/mL) & $\begin{array}{l}2408[1078- \\
5538]^{-}\end{array}$ & $\begin{array}{l}2265[1052- \\
5523]\end{array}$ & $\begin{array}{l}1858[1082- \\
4749]\end{array}$ & 0.6 \\
\hline 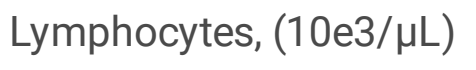 & $0.63[0.43-1.02]$ & $0.7[0.5-1.1]$ & $0.59[0.43-0.9]$ & 0.03 \\
\hline $\begin{array}{l}\mathrm{PaO} 2 / \mathrm{FiO} 2 \text { at ICU } \\
\text { admission }\end{array}$ & 110 [78-164] & $123[84-166]$ & $94[76-154]$ & 0.052 \\
\hline \multicolumn{5}{|c|}{$\begin{array}{l}\text { Categorical variables are expressed as frequency and percentage (\%), and continuous variables as } \\
\text { median and interquartile range } 25,75 \text { [IQR] }\end{array}$} \\
\hline
\end{tabular}

Multivariate analysis

Multivariate logistic regression showed that $\mathrm{PaO}_{2} / \mathrm{FiO}_{2}$ ratio at admission (OR 0.97 [0.94-0.99], $\mathrm{p}=$ 0.016), time to intubation (OR 1.01 [1.00-1.00], $p=0.013$ ), age (OR 1.09 [1.04-1.14], $p=0.001$ ), and angiotensin converting enzyme inhibitors (ACE) inhibitors use (OR 9.91 [2.15-45.7], $p=0.03$ ) were significantly associated with mortality. Other variables tested in the same model (D-dimer $(p=0.296)$, $\operatorname{LDH}(p=0.822)$, and lymphocytes count at admission $(p=0.644))$ did not reach statistical significance. However, the recent developed CALL score, which incorporated $\mathrm{PaO}_{2} / \mathrm{FiO}_{2}$ ratio, $\mathrm{LDH}$, age, lymphocytes 
count, and comorbidities, reached statistical significance in a multivariate model (OR 1.39 [1.06-1.82], $p$ $=0.018)$, as well as the D-dimer (OR 1.00 [1.00-1.00], $p=0.031)$.

We explored if number of days before hospital admission associated with outcome, but this variable did not show statistical significance, both as an individual one or as a part of an interaction term alongside with other variables, including time-to-intubation.

In another multivariate logistic regression, the $\mathrm{PaO}_{2} / \mathrm{FiO}_{2}$ ratio test $<100 \mathrm{mmHg}$ and late intubation as an interaction term were significantly associated with mortality in the ICU, with higher mortality in the group with $\mathrm{PaO}_{2} / \mathrm{FiO}_{2}$ ratio $<100$ with late intubation (Fig. 2). In addition, patients with late intubation exhibited lower compliance and driving pressure on the first $\mathrm{MV}$ day compared to the early intubated group, while $\mathrm{PaO}_{2} / \mathrm{FiO}_{2}$ ratio, and height-adjusted tidal volume were similar (Table 2). 
Table 2

Mechanical ventilation variables according to study group at day 1

\begin{tabular}{|c|c|c|c|c|c|c|}
\hline & \multicolumn{3}{|c|}{ All Ventilated Patients } & \multicolumn{3}{|c|}{$\mathrm{PaO} 2 / \mathrm{FiO} 2<100 \mathrm{mmHg}$} \\
\hline & $<72$ & $>72$ & $\begin{array}{l}\mathrm{P} \text { - } \\
\text { value }\end{array}$ & $<72$ & $>72$ & $\begin{array}{l}\mathrm{P}- \\
\text { value }\end{array}$ \\
\hline Respiratory Rate & 26 [24-28] & $\begin{array}{l}26[24- \\
30]\end{array}$ & 0.4 & $\begin{array}{l}26[23- \\
30]\end{array}$ & $\begin{array}{l}28[24- \\
30]\end{array}$ & 0.6 \\
\hline Tidal Volume (ml) & $\begin{array}{l}400[351- \\
430]\end{array}$ & $\begin{array}{l}380 \\
{[320-} \\
400]\end{array}$ & 0.1 & $\begin{array}{l}380[342- \\
400]\end{array}$ & $\begin{array}{l}354[307- \\
400]\end{array}$ & 0.1 \\
\hline $\begin{array}{l}\text { Tidal Volume/ Ideal Body } \\
\text { Weight }(\mathrm{ml} / \mathrm{kg})\end{array}$ & $\begin{array}{l}6.2[5.8- \\
6.8]\end{array}$ & $5.9[5-6.5]$ & 0.2 & $\begin{array}{l}5.9[5.7- \\
6.3]\end{array}$ & $5.6[5-6.2]$ & 0.2 \\
\hline PEEP (cmH20) & $10[8-10]$ & $8[6-10]$ & 0.01 & $10[8-12]$ & $8[6-10]$ & 0.02 \\
\hline P Plateau (cmH20) & 20 [19-23] & $\begin{array}{l}21[19- \\
24]\end{array}$ & 0.4 & $\begin{array}{l}21[18- \\
24]\end{array}$ & $\begin{array}{l}22[20- \\
24]\end{array}$ & 0.3 \\
\hline $\operatorname{Crs}(\mathrm{ml} / \mathrm{cmH} 20)$ & $33[39-40]$ & $\begin{array}{l}32[22- \\
38]\end{array}$ & 0.06 & $\begin{array}{l}32[30- \\
39]\end{array}$ & $\begin{array}{l}25[20- \\
34]\end{array}$ & 0.01 \\
\hline Driving Pressure $(\mathrm{cmH} 20)$ & $11[10-13]$ & $\begin{array}{l}12[10- \\
15]\end{array}$ & 0.08 & $12[9-13]$ & $13[11-17]$ & 0.02 \\
\hline $\mathrm{PaO}_{2} / \mathrm{FiO}_{2}$ ratio $(\mathrm{mmHg})$ & $\begin{array}{l}163[124- \\
200]\end{array}$ & $\begin{array}{l}130 \\
{[107-} \\
170]\end{array}$ & 0.01 & $\begin{array}{l}132[89- \\
173]\end{array}$ & $\begin{array}{l}120[96- \\
143]\end{array}$ & 0.5 \\
\hline $\mathrm{pH}$ & $\begin{array}{l}7.34 \\
{[7.28-} \\
7.40]\end{array}$ & $\begin{array}{l}7.33 \\
{[7.26-} \\
7.4]\end{array}$ & 0.7 & $\begin{array}{l}7.37 \\
{[7.28-} \\
7.43]\end{array}$ & $\begin{array}{l}7.36 \\
{[7.26-7.4]}\end{array}$ & 0.7 \\
\hline $\mathrm{PaCO} 2(\mathrm{mmHg})$ & $45[38-51]$ & $\begin{array}{l}48[42- \\
58]\end{array}$ & 0.02 & $\begin{array}{l}49[38- \\
54]\end{array}$ & $\begin{array}{l}47[41- \\
61]\end{array}$ & 0.4 \\
\hline \multicolumn{7}{|c|}{$\begin{array}{l}\text { Categorical variables are expressed as frequency and percentage (\%), and continuous variables as } \\
\text { median and interquartile range } 25,75 \text { [IQR] }\end{array}$} \\
\hline
\end{tabular}


Table 3

Outcomes by time from ICU admission to intubation.

\begin{tabular}{|c|c|c|c|c|}
\hline & All & $\begin{array}{l}<72 \text { hours to Ol } \\
\text { № } 100\end{array}$ & $\begin{array}{l}>72 \text { hours to Ol } \\
\text { № } 83\end{array}$ & P-value \\
\hline 28-day Mortality (\%) & $39(21 \%)$ & $14(14 \%)$ & $25(30 \%)$ & 0.008 \\
\hline ICU Mortality (\%) & $56(31 \%)$ & $21(21 \%)$ & $35(41 \%)$ & 0.002 \\
\hline HFNC pre-OI (\%) & $109(60 \%)$ & $38(37 \%)$ & $71(88 \%)$ & 0.001 \\
\hline Prone position (\%) & $130(71 \%)$ & $71(71 \%)$ & $59(71 \%)$ & 0.99 \\
\hline Tracheostomy (\%) & $45(25 \%)$ & $21(21 \%)$ & $24(29 \%)$ & 0.22 \\
\hline MV Days (days) & 14 [8-29] & $13[8-25]$ & $17[9-33]$ & 0.23 \\
\hline Ventilator-free days (days) & $14[0-20]$ & $15[3-20]$ & $12[0-20]$ & 0.28 \\
\hline RRT (\%) & $24(13 \%)$ & $13(13 \%)$ & $11(13 \%)$ & 0.96 \\
\hline ICU LOS (days) & 18 [9-33] & $15[9-27]$ & $23[12-37]$ & 0.01 \\
\hline Hospital LOS (days) & $32[21-52]$ & $31[18-48]$ & $36[24-56]$ & 0.02 \\
\hline \multicolumn{5}{|c|}{$\begin{array}{l}\text { Categorical variables are expressed as frequency and percentage (\%), and continuous variables as } \\
\text { median and interquartile range } 25,75 \text { [IQR] }\end{array}$} \\
\hline
\end{tabular}

Time-to-intubation was also associated with significant differences on early arterial pCO2, arterial pH, tidal volume and pulmonary Crs (Additional file 2).

\section{Discussion}

Our main finding is that among hospitalized patients with COVID-19 and requiring MV, intubation after 72 hours of hospital admission and $\mathrm{PaO}_{2} / \mathrm{FiO}_{2}$ ratio on admission $<100 \mathrm{mmHg}$ was associated with increased mortality. In addition, age $>60$ years-old, and previous use of ACE inhibitors were also associated with increased mortality.

The timing of intubation in patients with COVID-19 has been the subject of intense debate. While some advocate for early intubation, others claim for a more conservative approach, trying noninvasive methods (NIV, HFNC and prone) (22) to prevent intubation an connection to MV (23). In our patients, the decision to intubate was based on clinical judgment and may express different clinical tracks of these patients (24). Some were admitted with overt respiratory failure, others progressed steadily to respiratory failure, while others deteriorated after an initial period of improvement. 
Furthermore, patients intubated after 72 hours and with a $\mathrm{PaO} 2$ / FiO2 ratio $<100 \mathrm{mmHg}$ exhibited lower pulmonary $\mathrm{Crs}$, lower $\mathrm{pH}$, and higher pCO2 after intubation. Clearly, these patients were sicker and developed a progression of their disease. However, we cannot establish the true reason for this progression, which could be explained by the natural evolution of the disease or it could be a phenotype with a specific progression trajectory, but which is also not explained by what was described at the beginning of the pandemic (25). Another probable cause could be given by the spontaneous unregulated ventilatory effort for prolonged periods of time and that would be capable of inducing the progression of lung damage, what we currently known as patient self-inflicted lung injury (P-SILI) (26)(27). Considering that the current knowledge on the role of P-SILI in the progression of lung disease is very limited and there are many aspects of it that are still under debate (22), this would not provide justification for liberal use of endotracheal intubation (22)(28).

Our findings differ from the results reported by a recent study addressing the impact of the time from ICU admission to intubation on outcome (18). In this study the median from hospital to ICU admission was 1.0 days. In consequence, in this short time frame an intubation at 8 or 24 hours did not produce a significant difference in outcome. We can speculate that the small period of time between hospital admission to ICU admission could have effectively limited the damage an eventual P-SILI could provoke after a longer time of spontaneous or assisted ventilation in hypoxemic COVID-19 patients.

Almost half of the total number of patients with $\mathrm{PaO}_{2} / \mathrm{FiO}_{2}$ ratio $<200 \mathrm{mmHg}$ admitted to our center did not require MV. Most of them underwent a trial of awake prone and/or HFNC for the management of respiratory failure. These findings confirmed that the use of awake prone and/or HFNC may be useful in COVID-19 patients with respiratory failure as have been published (29)(12)(10). Although it is true, patient with PAFI $<100$ at admission and who were intubated after 72 hours, a prone and HFNC trial could help a significant number of patients avoid intubation and its potential complications without an increase in mortality (29), especially in a pandemic situation.

Our study has several limitations. First, it is a single center cohort study, in a tertiary academic hospital, not reflecting necessarily the reality of other hospitals in our country, in which prioritization and triage of MV was even more demanding. Second, we followed a ventilatory management protocol that included HFNC trial, awake proning position, prolonged proning cycles, and ultra-protective ventilation, among other interventions. Notwithstanding that this protocol has physiological and clinical rationale, and is evidence-supported, it could differ from other centers' algorithms, hindering the external validity of our results. Finally, as we previously mentioned, our results are only hypothesis generating, but provide mounting evidence to guide future decision-making and promote further clinical research.

\section{Conclusion}

In conclusion, we found that hospitalized patients with COVID-19 admitted with $\mathrm{PaO} 2$ / FiO2 $<100 \mathrm{mmHg}$ and intubated 72 hours after hospital admission had an increase in mortality. Other identifiable risk factors on admission, such as age $>60$ years and the use of ACE inhibitors, may increase the risk 
associated with late intubation. Further studies are required to confirm our findings and establish the best time for intubation in COVID-19 patients admitted with moderate to severe ARDS, as well as a more appropriate ventilatory approach and support.

\section{Abbreviations}

ARDS, Acute respiratory distress syndrome.

ICU, Intensive care unit.

WOB, work of breathing.

HFNC, high-flow nasal cannula.

MV, Mechanical ventilation.

P-SILI, self-inflicted lung injury by the patient.

RT-PCR, reverse transcriptase polymerase chain reaction.

Crs, Respiratory system compliance.

PEEP, Positive end-expiratory pressure

ECMO, extracorporeal membrane oxygenation.

APACHE, Acute Physiology and Chronic Health Evaluation.

SOFA, Sequential Organ Failure Assessment.

ACE inhibitors, angiotensin converting enzyme inhibitors.

\section{Declarations}

Ethics approval and consent to participate

The Institutional Ethics Committee approved this project (Research Ethics Committee № 200504004 , Faculty of Medicine, Pontificia Universidad Católica de Chile), and waived the need for informed consent.

Consent for publication

Not applicable.

Availability of data and materials 
The data that support the findings of this study are available from the corresponding author upon reasonable request.

Competing interests

The authors declare that they have no competing interests.

Funding

None.

Authors' contributions

$\mathrm{MV}$ and $\mathrm{RC}$ are guarantors of the entire manuscript; $\mathrm{MV}, \mathrm{RC}, \mathrm{EK}, \mathrm{GH}$ and $\mathrm{GB}$

designed the study; MV, EK, BL, PB, ER, AN, IR, MA, EE, LR, GH and RC collected and analyzed all the data. All the authors helped in the data interpretation and the manuscript draft. All authors read and approved the final manuscript.

Acknowledgements

None.

Authors details

${ }^{1}$ Departamento de Medicina Intensiva, Pontificia Universidad Católica de Chile, Avenida Diagonal Paraguay 362, Santiago, Chile 8330077

${ }^{2}$ Facultad de Medicina, Pontificia Universidad Católica de Chile, Avenida Diagonal Paraguay 362, Santiago, Chile 8330077

${ }^{3}$ Sección Medicina de Urgencia, Departamento de Medicina Interna, Pontificia Universidad Católica de Chile, Avenida Diagonal Paraguay 362, Santiago, Chile 8330077

${ }^{4}$ Departamento de Medicina Interna, Pontificia Universidad Católica de Chile, Avenida Diagonal Paraguay 362, Santiago, Chile 8330077

\section{References}

1. Grasselli G, Zangrillo A, Zanella A, Antonelli M, Cabrini L, Castelli A, et al. Baseline Characteristics and Outcomes of 1591 Patients Infected with SARS-CoV-2 Admitted to ICUs of the Lombardy Region, Italy. JAMA - Journal of the American Medical Association. 2020;323(16):1574-81.

2. Botta M, Tsonas AM, Pillay J, Boers LS, Algera AG, Bos LDJ, et al. Ventilation management and clinical outcomes in invasively ventilated patients with COVID-19 (PRoVENT-COVID): a national, 
multicentre, observational cohort study. The Lancet Respiratory Medicine. 2020;19(20):1-10.

3. Wang Y, Lu X, Li Y, Chen H, Chen T, Su N, et al. Clinical course and outcomes of 344 intensive care patients with COVID-19. Am J Respir Crit Care Med. 2020;201(11):1430-4.

4. Sauld S, Caridi-Scheible M, Blum JM, Robichaux C. ICU and Ventilator Mortality Among Critically III Adults With Coronavirus Disease 2019. Critical care medicine [Internet]. 2020;48(9). Available from: www.ccmjournal.org.

5. Dhont S, Derom E, Van Braeckel E, Depuydt P, Lambrecht BN. The pathophysiology of "happy" hypoxemia in COVID-19. Respir Res. 2020;21(1):1-9.

6. Tobin MJ, Laghi F, Jubran A. Why. COVID-19 silent hypoxemia is baffling to physicians. Am J Respir Crit Care Med. 2020;202(3):356-60.

7. Jounieaux V, Rodenstein DO, Mahjoub Y. On Happy Hypoxia and on Sadly Ignored "Acute Vascular Distress Syndrome" in Patients with COVID-19. American Journal of Respiratory and Critical Care Medicine [Internet]. 2020;202(11):1598-9. Available from: https://science.sciencemag.org/content/368/6490/455/tab-e-letters.

8. Chiumello D, Brioni M. Severe hypoxemia: Which strategy to choose. Critical Care [Internet]. 2016;20(1):1-9. Available from: http://dx.doi.org/10.1186/s13054-016-1304-7.

9. Brochard L, Slutsky A, Pesenti A. CRITICAL CARE PERSPECTIVE Mechanical Ventilation to Minimize Progression of Lung Injury in Acute Respiratory Failure. 2017 [cited 2021 Jan 10]; Available from: www.atsjournals.org.

10. Rochwerg B, Einav S, Chaudhuri D, Mancebo J, Mauri T, Helviz Y, et al. The role for high flow nasal cannula as a respiratory support strategy in adults: a clinical practice guideline. Intensive Care Medicine [Internet]. 2020;46:2226-37. Available from: https://doi.org/10.1007/s00134-020-06312-y.

11. Raoof S, Nava S, Carpati C, Hill NS. High-Flow, Noninvasive Ventilation and Awake (Nonintubation) Proning in Patients With Coronavirus Disease 2019 With Respiratory Failure. Chest [Internet]. 2020;158(5):1992-2002. Available from: https://doi.org/10.1016/j.chest.2020.07.013.

12. Weatherald J, Solverson K, Zuege DJ, Loroff N, Fiest KM, Parhar KKS. Awake prone positioning for COVID-19 hypoxemic respiratory failure: A rapid review. Journal of Critical Care [Internet]. 2021;61:63-70. Available from: https://doi.org/10.1016/j.jcrc.2020.08.018.

13. Kobayashi H, Uchino S, Takinami M, Uezono S. The Impact of Ventilator-Associated Events in Critically III Subjects With Prolonged Mechanical Ventilation. 2017.

14. Finfer SR, Vincent J-L, Slutsky AS, Ranieri VM. Critical Care Medicine Ventilator-Induced Lung Injury. N Engl J Med. 2013;369:2126-62.

15. Gattinoni L, Marini JJ, Collino F, Maiolo G, Rapetti F, Tonetti T, et al. The future of mechanical ventilation: lessons from the present and the past.

16. Megan R, Valerie G, Ashish J. Critical supply shortages-The need for ventilators and personal protective equipment during the Covid-19 pandemic. 2020;41(1):1489-91. 
17. Kangelaris KN, Ware LB, Wang CY, Janz DR, Zhuo H, Matthay MA, et al. Timing of intubation and clinical outcomes in adults with acute respiratory distress syndrome. Crit Care Med. 2016;44(1):1209.

18. Hernandez-Romieu AC, Adelman MW, Hockstein MA, Robichaux CJ, Edwards JA, Fazio JC, et al. Timing of intubation and mortality among critically ill coronavirus disease 2019 patients: A singlecenter cohort study. Critical Care Medicine. 2020;E1045-53.

19. Ranieri VM, Rubenfeld GD, Thompson BT, Ferguson ND, Caldwell E, Fan E, et al. Acute respiratory distress syndrome: The Berlin definition. JAMA - Journal of the American Medical Association. 2012;307(23):2526-33.

20. Knaus WA, Draper EA, Wagner DP, Zimmerman JE. APACHE II: A severity of disease classification system. Critical Care Medicine [Internet]. 1985 [cited 2021 Feb 14];13(10):818-29. Available from: https://pubmed.ncbi.nlm.nih.gov/3928249/.

21. Vincent J-L, Moreno R, Takala J, Willatts S, De Mendon a A, Bruining H, et al. The SOFA (Sepsis.related Organ Failure Assessment) score to describe organ dysfunction/failure. Vol. 22, Intensive Care Med. Springer-Verlag; 1996.

22. Tobin MJ, Laghi F, Jubran A. Caution about early intubation and mechanical ventilation in COVID-19. Ann Intensive Care [Internet]. 2020;10:78. Available from: https://doi.org/10.1186/s13613-02000692-6.

23. Tobin MJ. Basing Respiratory Management of COVID-19 on Physiological Principles. Am J Respir Crit Care Med [Internet]. 2020;201(11):1319-36. Available from: www.atsjournals.org.

24. Tobin MJ. Pondering the atypicality of ARDS in COVID-19 is a distraction for the bedside doctor. 2021; Available from: https://doi.org/10.1007/s00134-020-06340-8.

25. Gattinoni L, Chiumello D, Caironi P, Busana M, Romitti F, Brazzi L, et al. COVID-19 pneumonia: different respiratory treatments for different phenotypes? Intensive Care Medicine [Internet]. 2020;46(6):1099-102. Available from: https://doi.org/10.1007/s00134-020-06033-2.

26. Brochard L. Ventilation-induced lung injury exists in spontaneously breathing patients with acute respiratory failure: Yes. Vol. 43, Intensive Care Medicine. 2017. p. 250-2.

27. Van Haren F, Pham T, Brochard L, Bellani G, Laffey J, Dres M, et al. Spontaneous Breathing in Early Acute Respiratory Distress Syndrome: Insights from the Large Observational Study to UNderstand the Global Impact of Severe Acute Respiratory FailurE Study*. Critical Care Medicine [Internet]. 2019;47(2):229-38. Available from: http://links.Iww.

28. Tobin MJ, Laghi F, Jubran A. P-SILI is not justification for intubation of COVID-19 patients. Ann Intensive Care [Internet]. 2020;10:105. Available from: https://doi.org/10.1186/s13613-020-00724-1.

29. Demoule A, Baron AV, Darmon M, Beurton A, Géri G, Voiriot G, et al. High-flow nasal cannula in critically III patients with severe COVID-19. Am J Respir Crit Care Med. 2020;202(7):1039-42.

\section{Figures}




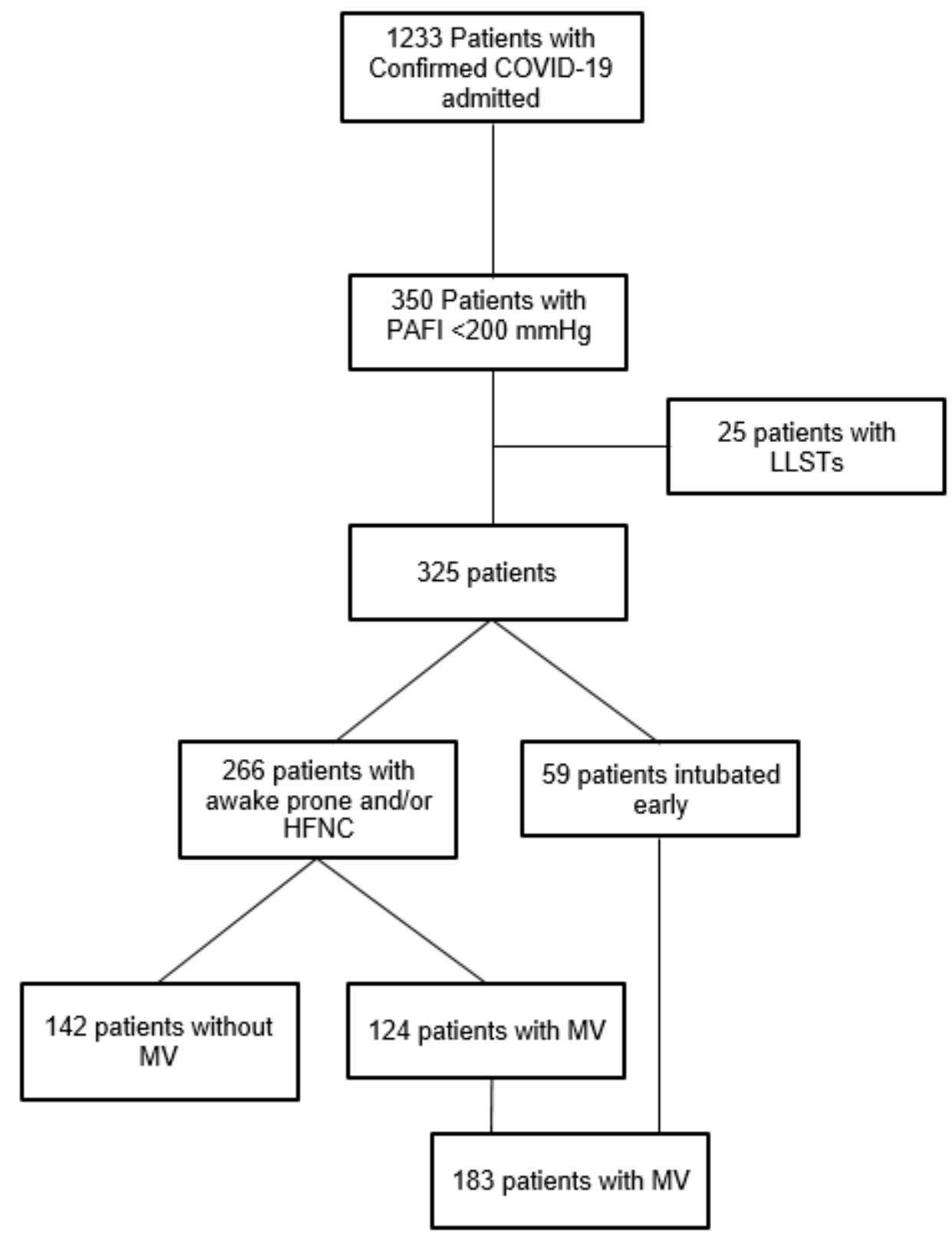

Figure 1

COVID-19 patients' enrollment and inclusion in the analysis Abbreviations: LLSTs, limitation on life support techniques; HFNC, high-flow nasal cannula; MV, mechanical ventilation. 


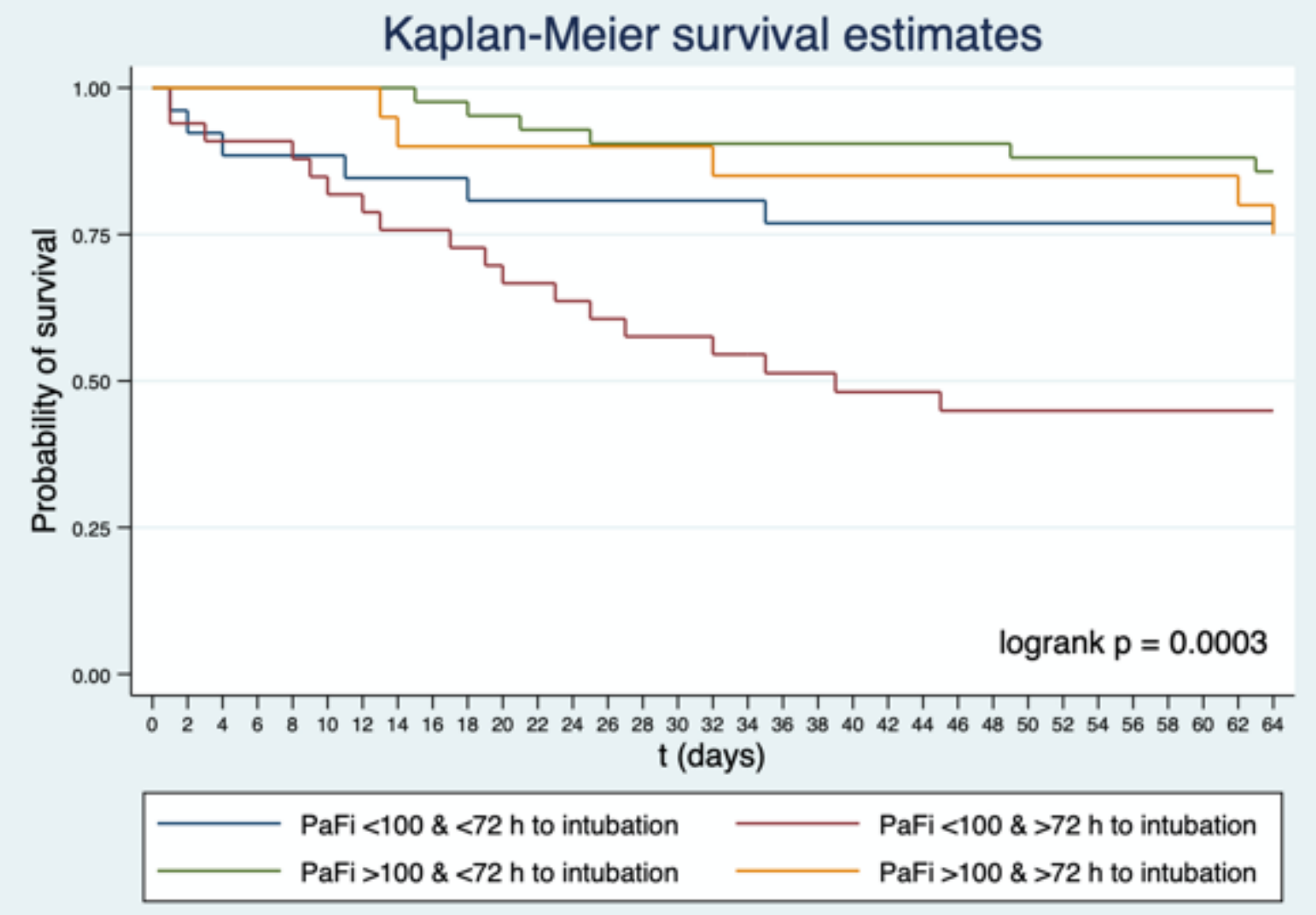

Figure 2

Kaplan-Meier survival curve according timing of intubation and $\mathrm{PaO} 2 / \mathrm{FiO} 2$ ratio. The probability of hospital death was higher in severe intubated ARDS after 72 hours.

\section{Supplementary Files}

This is a list of supplementary files associated with this preprint. Click to download.

- Additionalfile1.docx

- Additionalfile2.docx 